\title{
Prevalence and Pharmacotherapeutic Management of Pediatric Psoriasis-A Descriptive Review
}

\author{
Ahmed A. Albarraq, Saad S. Alqahtani, Sarfaraz Ahmad, David Banji \\ Pharmacy Practice Research Unit, Department of Clinical Pharmacy, College of Pharmacy, Jazan University, Jizan, KSA.
}

\begin{abstract}
Psoriasis is an auto-immune chronic inflammatory skin disease, which affects about $3.5 \%$ of the world's population. Prevalence of psoriasis among children aged 0 to 18 years is $1 \%$ in the United State of America, $5.3 \%$ in eastern Saudi Arabia and is on constant rise in other parts of the world. An effective treatment of psoriasis in children may often be challenging mainly because of the lack of established therapeutic guidelines. The objective of this review, therefore, is to provide an update on the prevalence and the pharmacotherapeutic management of pediatric psoriasis, which could be beneficial to clinical pharmacists and other healthcare workers. This multifactorial papulosquamous disorder is linked with the genetic makeup of an individual although the various risk factors like obesity, stress, emotional imbalance, psychological disturbances, cold weather, skin irritation, infection in the respiratory tract and the presence of hemolytic streptococcus could trigger psoriasis. Plaque psoriasis is the most common; but, guttate, pustular disease, erythrodermic (red skin) and rheumatoid psoriasis diseases are also noticed in children. The successful approach for treating psoriasis in children depends on the precise selection of line of therapy on case-by-case basis to enhance benefit-risk ratio, with careful attention of its impact on the patient and family. Therefore, treatment of pediatric psoriasis must be rationalized based on the type and intensity of the disease to reduce probable side effects of drugs in children.
\end{abstract}

Key words: Psoriasis, Pediatric, Rational, Autoimmune disease, Dermatological, Prevalence.

\section{INTRODUCTION}

Psoriasis is an autoimmune dermatological disorder characterized by hyper-proliferation of skin cell..$^{1}$ It is a prolonged, painful, disabling, non-communicable and physiologically disturbing disease. ${ }^{2}$ It can occur throughout the body, but usually affects the nails, toes, scalp, knees and elbow. ${ }^{3}$ General occurrence of psoriasis in the United State of America is about $2.5 \% .{ }^{4,5}$ prevalence among children aged 0 to 18 years is $1 \%$; and, the incidence is 40.8 per one hundred thousand $(100,000) .{ }^{6}$ Whereas, the percentage of occurrence in eastern Saudi Arabia is about $5.3 \%$ and the family history of psoriasis is 8.4\% in Saudi Arabia. ${ }^{7}$ The 10\% incidence of childhood psoriasis is reported in Saudi Arabia, ${ }^{8}$ which occurred before the age of 10 years and $2 \%$ at less than 2 years of age. ${ }^{9-11}$
Psoriasis shows a bimodal age group distribution; ${ }^{12}$ the first modal being pediatric psoriasis that arises under 18 years of age and the second is adult psoriasis that occurs over 18 years. ${ }^{13}$ Pediatric psoriasis is further classified as (i) Infantile psoriasis, which occurs in the first year and is a self-limiting condition; (ii) Proleptical psoriasis; and (iii) arthritic-psoriasis. ${ }^{14,15}$

Inborn psoriasis has scanty incidence with appropriate family history. ${ }^{16}$ It involves a dissimilar outline of anatomic development, a large portion of erythrodermic, linear or pustular subtypes with a low prognosis. ${ }^{17}$ Hence, inborn psoriasis is characterized by scaling, erythematous or pustular occurrence in the neonates. ${ }^{18}$ It may appear at any stage of life and is much more common in
Submission Date: 02-04-2019; Revision Date: 12-06-2019; Accepted Date: 26-07-2019

DOI: 10.5530/ijper.53.4.118 Correspondence: Dr. David Banji, Pharmacy Practice Research Unit, Department of Clinical Pharmacy, College of Pharmacy, Jazan University, Jizan, KSA.

Phone: +966-557942809 E-mail: davidbanji@gmail. com

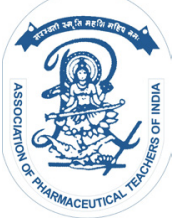

www.ijper.org 
the age group of 50-69 years. ${ }^{19}$ Incidence of this form of psoriasis may vary from $0.09 \%$ to $11.4 \%$ worldwide, thereby, making it a serious global issue. ${ }^{20}$ Psoriatic pediatric patients may have high risk of developing other serious clinical co-morbid conditions. ${ }^{21}$ They could concomitantly suffer from psoriatic arthritis, anxiety, depression, obesity, hypertension, dyslipidemia, nonalcoholic fatty liver disorder, diabetes mellitus (DM) type-2 and decrease quality of life. ${ }^{22}$ Among the afflicted patients, about thirty-three percent of patients develop symptoms at an early age of life, while others remain symptomless until they approach adulthood. ${ }^{23}$

Social stigma and rejection are main issues with psoriasis. ${ }^{24}$ Loneliness, segregation and unattractiveness are manifested in the affected. ${ }^{24}$ There are greater possibilities of depression, disability and loss of playful life among pediatric patients. ${ }^{25}$ In addition, high therapeutic expenses can add to the socioeconomic burden on parents. ${ }^{26}$ Psoriasis in these patients is not just difficult for the victim; but, it could be serious for others also. ${ }^{27}$ Children may feel self-conscious, emotional, exhibit low self-esteem and finally, leading to the development of several co-morbid conditions in children. ${ }^{28}$ It, therefore, is suggested that an early detection of diseases may be a significant approach to delay or prevent considerable co-morbidities and to reduce the burden of disease. ${ }^{29}$ Another noticeable feature of this disease is that it might get better or worse as it could disappear or reappear suddenly. ${ }^{30}$

The objective of this review article, therefore, is to provide an update on the rational approach for the treatment of childhood psoriasis with careful consideration of symptoms of the disease, which can benefit clinical pharmacists and other healthcare workers.

\section{Incidence and prevalence of the disease}

Psoriasis could occur from four days to fourteen years of age. ${ }^{31}$ The average age of appearance of the disease in boys it peaks at the age of 6-10 years. ${ }^{31}$ however, for girls, it appears at 10-14 years. ${ }^{32}$ Lifetime occurrence of psoriasis at the age group $0-17$ years was $1.37 \%$ in Taiwan and China. ${ }^{33}$ Study on 277 pediatric psoriatic patients in China revealed an average age of onset of disease and occurrence ratio between male and female were found to be 11 years and 1:1 respectively. ${ }^{34}$ In another cohort study in the USA, the annual prevalence of pediatric psoriasis was 40.8 per 100,000 in patients less than 18 years of age. ${ }^{35}$ Further, it was observed that the magnitude of suffering was equal in both males and females and prevalence of childhood psoriasis increased as age advanced with no particular peaks in disease condition. ${ }^{36}$ Similarly, there was no difference found in occurrence of pediatric psoriasis between male 23 $(37.7 \%)$ and female patients $38(62.3 \%)$ under 18 years of age in Turkey. ${ }^{37}$

\section{Etiology}

The genetic characteristics and involvement of the immune system of an individual might be the reasons for its auto-immune disease status; however, ${ }^{38}$ psoriasis can easily be aggravated by many triggering agents like stress, trauma, excess exposure to sun, chronic infections and usage of a certain category of systemic drugs. ${ }^{39}$ The defensive action of $\mathrm{T}$ lymphocytes against microorganisms and mistaken action of immune cells against healthy cells of skin are the other possibilities for sudden eruption of psoriasis. ${ }^{40,41}$

\section{Precipitating factors}

Obesity in children is considered as one of the precipitating factors for onset of psoriasis at an early age. ${ }^{42}$ Emotional stress, psychiatric morbidity are the other factors can precipitate psoriasis to the extent of $14.8 \%$ and $9.8 \%$, respectively. ${ }^{1,43}$ Upper respiratory infection is another risk factor for psoriasis in children. ${ }^{44}$ Triggering factors for generalized pustular psoriasis is depicted in Figure 1

\section{Clinical presentation}

Plaque-type of psoriasis in young patients has matching pattern (68\%) with adults, which is usually seen on the scalp, elbows, knees and the post-auricular region. ${ }^{45}$ The other types of pediatric psoriasis are: 1. Guttate disease (28.9\%); 2. Erythroderma (1.4\%); 3. Pustular disease including palmoplantar pustular psoriasis $(1.1 \%)$ and 4 . Mucosal glossitis $(1.1 \%)^{46}$ Generalized pustular psoriasis is rare in children; but, if present, it may pose as a

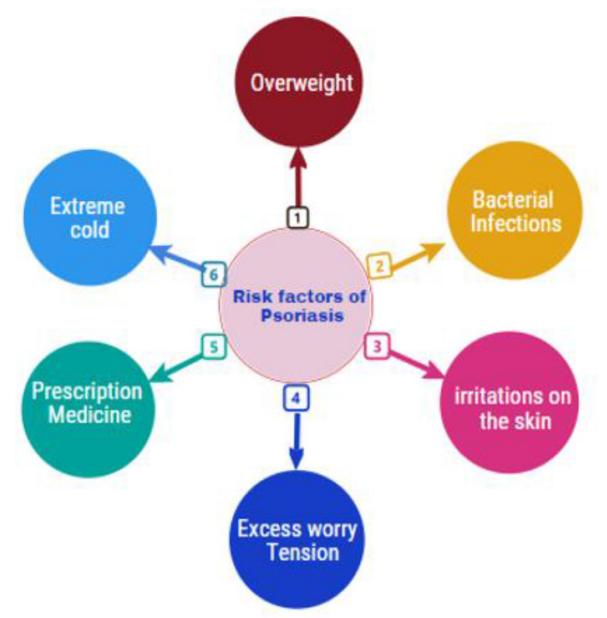

Figure 1: Risk factors of Psoriasis. 
serious life-threatening threat. ${ }^{47}$ Psoriasis can be characterized by distinct symptoms as indicated in Figure 2.48 Based on the Psoriasis Area and Severity Index (PASI), calculated by considering the affected body area and co-existence of psoriatic arthritis, psoriasis is graded as (1) Mild - if it is under 3\% body surface area; (2) Medium or moderate - between 3\% -10 \% and (3) Severe - above $10 \%$ is used to assess the severity of the disease. ${ }^{49}$

The most common symptoms such as skin scaling, itching, erythema, fatigue, swelling, burning sensation, bleeding can occur among $92 \%, 72 \%, 69 \%, 27 \%, 23 \%$, $20 \%$ and $20 \%$ of the affected individuals respectively and scaling of skin in the non-scalp area and scalp areas to the extent of $89 \%$ and $62 \%$ respectively. ${ }^{50,51}$ Nail psoriasis prevailed among $4.2 \%-69 \%$ of the affected individuals. ${ }^{52,53}$

\section{Treatment}

Many therapeutic choices are available for the treatment of psoriasis (Figure 2 and 3; Table 1) and different things work for different patients. ${ }^{53}$ Topical treatment will be the first preferred option in pediatric psoriasis and other treatments include systemic administration, based on the severity of disease.

\section{Topical treatment}

Dermal applications are used to treat mild to moderate types of psoriasis. ${ }^{56}$ There are different types of agents available that can be regularly used as topical therapies

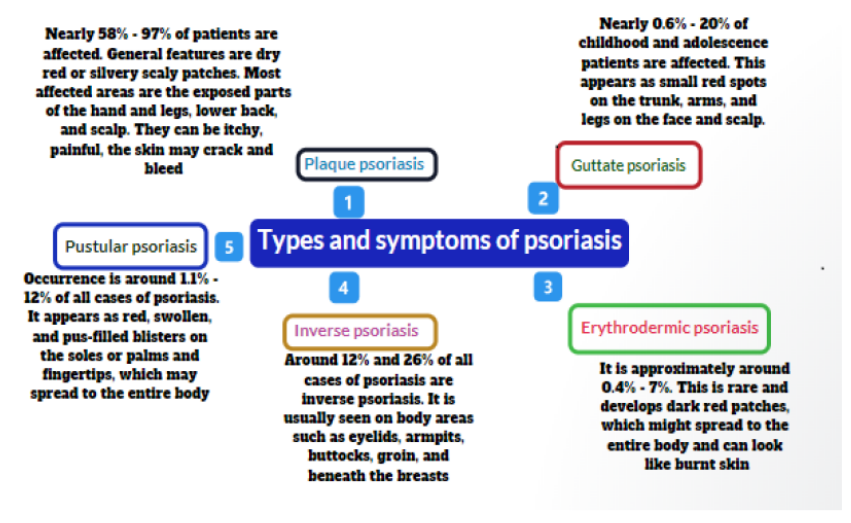

Figure 2: Types and symptoms of psoriasis.

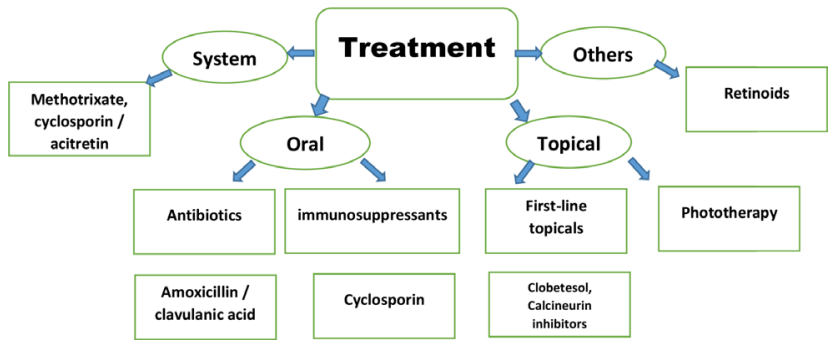

Figure 3: Treatment options.

for treating pediatric psoriasis. ${ }^{57}$ The different topical anti-psoriatic applications are moisturizers, corticosteroids, vitamin $\mathrm{D}$ and salicylic acid or coal tar in the form of ointments, creams, shampoos and lotions. ${ }^{58}$ Topical steroids are generally recommended for atopic dermatitis. ${ }^{59}$ Long term application of potent steroids can lead to atrophy if a large area of the body surface is involved. Topical clobetasol is prescribed in children aged 12 and over. $^{60}$ Calcipotriene or calcitriol topical preparations can be used in the treatment of pediatric psoriasis; ${ }^{61}$ however, other formulations like anthralin or dithranol should preferably be avoided in pediatric patients due to its side effects. ${ }^{62}$ The other topical anti-psoriatic preparations like calcineurin inhibitors, tacrolimus and pimecrolimus can be considered in treating pediatric psoriasis $^{63,64}$ Table 2.

\section{Desquamation agents}

Desquamation agents such as salicylic acid, lactic acid and urea are indicated to remove the scales formed during psoriasis. ${ }^{65}$ They are more effective if they are used concurrently with anti-inflammatory agents like topical corticosteroids(TCS) and the analogs of vitamin D as topical preparation. ${ }^{66}$ Salicylic acid has distinctive beneficial effects in removing thick plaques formed on the scalp, soles and palms. ${ }^{64}$ However, it should be avoided in infants as it can causes percutaneous salicylism. ${ }^{67}$

\section{Light (Photo) therapy}

An exposure to ultraviolet (UV) light is another powerful treatment option available to treat psoriasis. ${ }^{68}$ Brief

\begin{tabular}{|c|c|c|c|c|c|}
\hline \multicolumn{5}{|c|}{ Table 1: WHO approved a list of medicines. ${ }^{54,55}$} \\
\hline Sr.No & Line of treatment & Category & Drug & Dose & Formulation \\
\hline 1 & Core list - for a basic health care system & $\begin{array}{c}\text { Anti-inflammatory } \\
\text { Antipruritic }\end{array}$ & Betamethasone & $0.1 \%$ (as Valerate) & Cream \\
\cline { 3 - 6 } & & Hydrocortisone & $1 \%($ acetate) & Cream \\
\hline 2 & $\begin{array}{c}\text { Complimentary list - Medicines required } \\
\text { for Systemic therapies, diagnostic, } \\
\text { monitoring, training or care. }\end{array}$ & Anthritic & methotrexate & $2.5 \mathrm{mg}$ & Tablet \\
\hline & & Immunosuppressants & cyclosporin & $25 \mathrm{mg}$ & capsule \\
\hline
\end{tabular}




\begin{tabular}{|c|c|c|c|c|c|}
\hline Sr. No. & $\begin{array}{l}\text { Category and its } \\
\text { potency }\end{array}$ & $\begin{array}{c}\text { Active } \\
\text { Agent(s) }\end{array}$ & Concentration & Formulation & Indications \\
\hline 1 & $\begin{array}{l}\text { Dermal } \\
\text { Corticosteroids } \\
\text { (low potency) }\end{array}$ & Desonide & $0.05 \%$ & $\begin{array}{c}\text { Ointment, } \\
\text { Cream, Lotion, Gel, Foam }\end{array}$ & $\begin{array}{c}\text { Sensitive area - groin, face, } \\
\text { axillae }\end{array}$ \\
\hline 2 & $\begin{array}{c}\text { Dermal } \\
\text { Corticosteroids } \\
\text { (Medium potency) }\end{array}$ & $\begin{array}{l}\text { Triamcinolone } \\
\text { acetonide }\end{array}$ & $\begin{array}{c}0.025 \% \\
0.1 \% \\
0.5 \%\end{array}$ & $\begin{array}{l}\text { Ointment, Solution, Cream, } \\
\text { Lotion, }\end{array}$ & $\begin{array}{c}\text { High-risk areas } \\
\text { (axillae, groin then decrease the } \\
\text { potency }\end{array}$ \\
\hline 3 & $\begin{array}{l}\text { Dermal } \\
\text { Corticosteroids } \\
\text { (High potency) }\end{array}$ & $\begin{array}{l}\text { Clobetasole } \\
\text { propionate }\end{array}$ & $0.05 \%$ & $\begin{array}{l}\text { Ointment, Cream, Solution, } \\
\text { Gel, Foam Spray, Shampoo }\end{array}$ & $\begin{array}{c}\text { Indicated in high risk and } \\
\text { sensitive areas } \\
\text { (axillae, groin then decrease the } \\
\text { potency }\end{array}$ \\
\hline 4 & $\begin{array}{l}\text { Analogues of } \\
\text { Vitamin D }\end{array}$ & Calcipotriene & $0.05 \%$ & Cream, Solution (scalP) & $\begin{array}{l}\text { Combined with dermal } \\
\text { corticosteroid for steroid- } \\
\text { separating effects }\end{array}$ \\
\hline 5 & Retinoid - topical & Tazarotene & $\begin{array}{c}0.05 \% \\
0.1 \%\end{array}$ & Gel & Preferred in psoriasis in adults. \\
\hline 6 & $\begin{array}{l}\text { Liquor Carbons } \\
\text { Detergents (LCD) / } \\
\text { Coal tar }\end{array}$ & $\begin{array}{l}\text { corticosteroid, } \\
\text { emollients, } \\
\text { lactic and } \\
\text { salicylic acid } \\
\text { (e.g. } 5 \% \\
\text { LCD in } 0.1 \% \\
\text { triamcinolone } \\
\text { ointment) }\end{array}$ & $\begin{array}{c}20 \% \text { LCD } \\
2 \% \text { crude coal tar } \\
\text { (CCT) } \\
5 \% \text { CCT } \\
10 \% \text { CCT }\end{array}$ & $\begin{array}{c}\text { Petrolatum } \\
\text { Aquaphor } \\
\text { Nutraderm lotion - Cetaphil } \\
\text { cream } 2 \%\end{array}$ & $\begin{array}{c}\text { Anti-inflammatory and keratolytic } \\
\text { action }\end{array}$ \\
\hline
\end{tabular}

exposure to UV light on a daily basis is beneficial; however, excess exposure can worsen the situation. ${ }^{69}$ Usage of laser therapy, concurrent therapies with UV light and dermal anti-psoriatic preparations on the affected skin are also beneficial. ${ }^{70}$ This therapy is advantageous and preferred line of treatment in children because of its safety, provided the protocol of phototherapy is followed. ${ }^{71}$

\section{Systemic treatment}

In uncontrolled and severe psoriasis, systemic treatment is considered as the last treatment option. ${ }^{72}$ the most preferred drugs in this line of treatment are immunosuppressive drugs like methotrexate, acitretin or cyclosporin along with oral antibiotics. ${ }^{73}$

\section{Oral antibiotics}

Oral antibiotics for short period of time is helpful in psoriasis if oral pharyngeal culture is positive. Erythromycin $(50 \mathrm{mg} / \mathrm{kg} / \mathrm{d})$ for fifteen days and, amoxicillin/ clavulanic acid ( $50 \mathrm{mg} / \mathrm{kg} / \mathrm{d}$ ) for twenty days is beneficial in the treatment of guttate psoriasis. ${ }^{74}$

\section{Cyclosporin}

Cyclosporin is useful in treating pediatric psoriasis in a dose ranging from $3-5 \mathrm{mg} / \mathrm{kg}$ body weight. ${ }^{75}$ However, its use is limited as it has a low therapeutic window and serious side effects; and if used, requires regular moni- toring of patients. Monitoring of high blood pressure and renal function tests is frequently required. ${ }^{76}$

\section{Retinoids}

Retinoids are useful in treating psoriasis; but, because of its severe side effects, they cannot be the first-line treatment in childhood psoriasis. ${ }^{77}$ Cheilitis, pruritus, hair loss, fragile skin and arthritis were other adverse effects often observed during the use of retinoids. ${ }^{78}$

\section{Methotrexate}

Methotrexate is extensively used to treat pediatric psoriasis ranging from moderate to severe types and found to be an outstanding therapeutic outcome at a dose of $0.2-0.7 \mathrm{mg} / \mathrm{kg} /$ per week. ${ }^{79}$ It is an effective option in severe conditions (PASI $\geq 10$ ). It is preferred over cyclosporin because of its advantage in managing psoriatic arthritis. ${ }^{80}$

\section{Biologics}

If conventional systemic drugs are ineffective, the biological agents are recommended to treat medium to serious type of psoriasis. ${ }^{81}$ The biological agents TNF- $\alpha$ inhibitors, etanercept and infliximab are currently in therapy to treat pediatric rheumatoid arthritis. ${ }^{82}$ These agents have satisfactory safety profile than classical systemic treatment and the option of this treatment depends on various other factors such as patient preferences, the speed of onset of action, side effects and the 
treatment cost. ${ }^{83} \mathrm{~A}$ recent expert opinion by Kaushik et al, suggested that Etanercept and Ustekinumab should be the preferred biologic agents to treat moderate to severe psoriasis and the traditional systemic agents (methotrexate, cyclosporine and acitretin) should be used only for a short term. ${ }^{84}$

\section{Natural supplements}

Antioxidants present in the food and food supplements may improve disease severity, though it cannot treat psoriasis on its own. ${ }^{85}$ It helps in keeping skin clear and can reduce pain at the joints. ${ }^{86}$ The other food supplements such as alpha-linolenic acid, Eicosapentaenoic acid (EPA), Docosahexaenoic acid (DHA) and Omega-3 fatty acids have desired and useful actions on body's immunity and are found effective in psoriatic patients. ${ }^{87}$

\section{CONCLUSION}

Psoriasis is a prolonged autoimmune dermatological disorder with great discomfort, but rarely a life-threatening disorder. The common precipitating factor includes stress, genetic predisposition and environmental factors. The treatment approach for pediatric psoriasis remains the same as adults but practitioner need to take care about unwanted effects of drugs. As the management of psoriasis is a long-term therapy, drugs with a narrow therapeutic index should be avoided to minimize vital organ complications. There is limited application of oral antibiotics; however, corticosteroids and vitamin D analogs can be effective in case of mild plaque psoriasis. Apart from this therapeutic approach, some dietary supplement like fish oil, EPA, DHA and phototherapy can be included in the plan of therapy to get an additive effect.

\section{ACKNOWLEDGEMENT}

The authors would like to express thanks to Prof. Otilia J F Banji for reviewing this manuscript, Dr. Nawazish Alam, Dr. Md. Sajid Ali and Dr. Sarfaraz Alam, College of Pharmacy, Jazan University, Jazan, KSA, for helping in reviewing literature sources for this manuscript.

\section{CONFLICT OF INTEREST}

The authors declare no conflict of interest.

\section{ABBREVIATIONS}

EPA: Eicosapentaenoic acid; CCT: Crude Coal Tar; DHA: Docosahexaenoic acid; DM: Diabetes Mellitus; LCD: Liquor Carbons Detergents; PASI: Psoriasis
Area and Severity Index; TCS: Corticosteroid; TNF $\alpha$ : Tumor Necrosis Factor-alpha; UV: Ultra Violet.

\section{REFERENCES}

1. Bhutto AM. Childhood psoriasis: A review of literature. Journal of Pakistan Association of Dermatology. 2016;21(3):190-7.

2. Benhadou F, Mintoff D, DelMarmol V. Psoriasis: Keratinocytes or Immune Cells-Which Is the Trigger?. Dermatology. 2019;235(2):91-100.

3. Mahé E, Maccari F, Beauchet A, Lahfa M, Barthelemy $\mathrm{H}$, Reguiaï Z, et al. Childhood-onset psoriasis: Association with future cardiovascular and metabolic comorbidities. British Journal of Dermatology. 2013;169(4):889-95.

4. Dreyer LN, Brown GC. Oral Manifestations of Psoriasis. The New York State Dental Journal. 2012;14-8.

5. Michalek IM, Loring B, John SM. A systematic review of worldwide epidemiology of psoriasis. Journal of the European Academy of Dermatology and Venereology. 2017;31(2):205-12.

6. Charbit L, Mahé E, Phan A, Chiaverini C, Boralevi F, Bourrat E, et al. Systemic treatments in childhood psoriasis: A French multicentre study on 154 children. British Journal of Dermatology. 2016;174(5):1118-21.

7. Munir S, Rahman S, Saba N, Ahmad W, Nilsson S, Mazhar K, et al. Association analysis of GWAS and candidate gene loci in a Pakistani population with psoriasis. Molecular Immunology. 2015;64(1):190-4.

8. Fatani MI, Abdulghani MH, Al-Afif KA. Psoriasis in the eastern Saudi Arabia. Saudi Medical Journal. 2002;23(2):213-7.

9. Alsuwaidan SN. Childhood psoriasis: Analytic retrospective study in Saudi patients. Journal of the Saudi Society of Dermatology and Dermatologic Surgery. 2011;15(2):57-61.

10. AlShammrie F, AIShammrie A. Pattern of skin disease in Hail region of Saudi Arabia. Journal of Dermatology and Dermatologic Surgery. 2017;21(2):62-5.

11. Amin TT, Ali A, Kaliyadan F. Skin disorders among male primary school children in Al Hassa, Saudi Arabia: Prevalence and socio-demographic correlates-a comparison of urban and rural populations. Rural Remote Health. 2011;11(1):1517.

12. Johnson MA, Armstrong AW. Clinical and histologic diagnostic guidelines for psoriasis: A critical review. Clinical Reviews in Allergy and Immunology. 2013:1;44(2):166-72.

13. Pourchot D, Bodemer C, Phan A, Bursztejn AC, Hadj-Rabia S, Boralevi F, et al. Nail psoriasis: A systematic evaluation in 313 children with psoriasis. Pediatric Dermatology. 2017;34(1):58-63.

14. Generali E, Ceribelli A, Stazi MA, Selmi C. Lessons learned from twins in autoimmune and chronic inflammatory diseases. Journal of Autoimmunity. 2017;83:51-61.

15. Armstrong AW, Wu J, Johnson MA, Grapov D, Azizi B, Dhillon J, et al. Metabolomics in psoriatic disease: Pilot study reveals metabolite differences in psoriasis and psoriatic arthritis. F1000Research. 2014;3:248.

16. Springate DA, Parisi R, Kontopantelis E, Reeves D, Griffiths CE, Ashcroft DM. Incidence, prevalence and mortality of patients with psoriasis: A UK population-based cohort study. British Journal of Dermatology. 2017;176(3):650-8.

17. Svendsen MT, Jeyabalan J, Andersen KE, Andersen F, Johannessen $H$. Worldwide utilization of topical remedies in treatment of psoriasis: A systematic review. Journal of Dermatological Treatment. 2017;28(5):374-83.

18. Reginatto FP, Villa DD, Cestari TF. Benign skin disease with pustules in the newborn. Anais Brasileiros De Dermatologia. 2016;91(2):124-34.

19. Parisi R, Symmons DP, Griffiths CE, Ashcroft DM. Global epidemiology of psoriasis: A systematic review of incidence and prevalence. Journal of Investigative Dermatology. 2013;133(2):377-85.

20. DeLaCruz C, DeCarvalho AV, Dorantes GL, Londoño GAM, Gonzalez C, Maskin $\mathrm{M}$, et al. Biosimilars in psoriasis: Clinical practice and regulatory perspectives in Latin America. The Journal of Dermatology. 2017;44(1):3-12.

21. Gisondi P, Galvan A, Idolazzi L, Girolomoni G. Management of moderate to severe psoriasis in patients with metabolic comorbidities. Frontiers in Medicine. 2015;2:1.

22. Lønnberg AS, Skov L. Co-morbidity in psoriasis: Mechanisms and implications for treatment. Expert Review of Clinical Immunology. 2017;13(1):27-34. 
23. Bilgic A, Bilgic Ö, Akış HK, Eskioğlu F, Kılıç EZ. Psychiatric symptoms and health-related quality of life in children and adolescents with psoriasis. Pediatric Dermatology. 2010;27(6):614-7.

24. Hrehorów E, Salomon J, Matusiak U, Reich A, Szepietowski JC. Patients with psoriasis feel stigmatized. Acta Dermato-Venereologica. 2012;92(1):67-72.

25. Basavaraj $\mathrm{KH}$, Navya MA, Rashmi R. Stress and quality of life in psoriasis: An update. International Journal of Dermatology. 2011;50(7):783-92.

26. Matterne $U$, Apfelbacher $C$. Peer-relationship-problems account for quality of life impairments in pediatric psoriasis. Journal of Psychosomatic Research. 2016;84:31-6.

27. Elman S, Hynan LS, Gabriel V, Mayo MJ. The 5-D itch scale: A new measure of pruritus. British Journal of Dermatology. 2010;162(3):587-93.

28. Gutmark-Little I, Shah KN. Obesity and the metabolic syndrome in pediatric psoriasis. Clinics in Dermatology. 2015;33(3):305-15.

29. Ryan C, Kirby B. Psoriasis is a systemic disease with multiple cardiovascular and metabolic comorbidities. Dermatologic Clinics. 2015;33(1):41-55.

30. Kuchekar AB, Pujari RR, Kuchekar SB, Dhole SN, Mule PM. Psoriasis: A comprehensive review. International Journal of Pharmacy and Life Sciences. 2011;2(6):857-77.

31. Warren RB, Kleyn CE, Gulliver WP. Cumulative life course impairment in psoriasis: patient perception of disease-related impairment throughout the life course. British Journal of Dermatology. 2011;164(Suppl 1):1-4.

32. Haug V, Benoit S, Wohlleben M, Hamm H. Annular pustular psoriasis in a 14-month-old girl: A therapeutic challenge. Journal of Dermatological Treatment. 2017;28(6):520-2

33. Michalek IM, Loring B, John SM. A systematic review of worldwide epidemiology of psoriasis. Journal of the European Academy of Dermatology and Venereology. 2017;31(2):205-12.

34. Fan X, Xiao FL, Yang S, Liu JB, Yan KL, Liang YH, et al. Childhood psoriasis: A study of 277 patients from China. Journal of the European Academy of Dermatology and Venereology. 2007;21(6):762-5.

35. Tollefson MM, Crowson CS, McEvoy MT, Kremers HM. Incidence of psoriasis in children: a population-based study. Journal of the American Academy of Dermatology. 2010;62(6):979-87.

36. Bronckers IM, Paller AS, Geel MJV, DeKerkhof PCV, Seyger MM. Psoriasis in children and adolescents: Diagnosis, management and comorbidities. Pediatric Drugs. 2015;17(5):373-84.

37. Elsner P, Diepgen TL, García-Doval HI, Langan MS, Nijsten LT, Hollestein RL. $2^{\text {nd }}$ European Dermato-Epidemiology Network (EDEN) Forum, 15-16. März 2018, Berlin. Dermatologie in Beruf und Umwelt. 2018;66(1):31.

38. Feinberg AN, Shwayder TA, Tareen R, Tempark T. Pediatric dermatologic disorders. Journal of Alternative Medicine Research. 2014;6(2):95.

39. Avelar AAD, Avelar AMM. Occupational Dermatosis. In Dermatology in Public Health Environments. 2018;641-58.

40. Baboota S, Alam MS, Sharma S, Sahni JK, Kumar A, Ali J. Nanocarrierbased hydrogel of betamethasone dipropionate and salicylic acid for treatment of psoriasis. International Journal of Pharmaceutical Investigation. 2011;1(3):139.

41. Ahmad S, Ali MS, Alam MS, Alam MI, Alam N. Nanoemulsionas a novel carrier for drug delivery system: An overview. Advances in Environmental Biology. 2016;10(10):120-31.

42. Tollefson MM, Crowson CS, McEvoy MT, Kremers HM. Incidence of psoriasis in children: a population-based study. Journal of the American Academy of Dermatology. 2010;62(6):979-87.

43. Carapeto FJ, Tomás L, Marrón SE, UK AF, Gieler U, Jemec G, et al. 14 Congress of the European Society for Dermatology and Psychiatry. Acta Derm Venereol. 2011;91:215-56.

44. Megna M, Napolitano M, Balato A, Scalvenzi M, Cirillo T, Gallo L, et al. Psoriasis in children: a review. Current Pediatric Reviews. 2015;11(1):10-26.

45. Silverberg NB. Pediatric psoriasis: An update. Therapeutics and Clinical Risk Management. 2009;5:849-56.

46. Sampogna F, Tabolli S, Söderfeldt B, Axtelius B, Aparo U, Abeni D. IDI Multipurpose Psoriasis Research on Vital Experiences (IMPROVE) investigators: Measuring quality of life of patients with different clinical types of psoriasis using the SF-36. British Journal of Dermatology. 2006;154(5):844-9.

47. DeOliveira ST, Maragno L, Arnone M, Fonseca TMD, Romiti R. Generalized pustular psoriasis in childhood. Pediatric Dermatology. 2010;27(4):349-54.
48. Raychaudhuri SK, Maverakis E, Raychaudhuri SP. Diagnosis and classification of psoriasis. Autoimmunity Reviews. 2014;13(4-5):490-5.

49. Robinson A, Kardos M, Kimball AB. Physician Global Assessment (PGA) and Psoriasis Area and Severity Index (PASI): why do both? A systematic analysis of randomized controlled trials of biologic agents for moderate to severe plaque psoriasis. Journal of the American Academy of Dermatology. 2012;66(3):369-75.

50. Pariser D, Schenkel B, Carter C, Farahi K, Brown TM, Ellis CN. Psoriasis Patient Interview Study Group: a multicenter, non-interventional study to evaluate patient-reported experiences of living with psoriasis. Journal of Dermatological Treatment. 2016;27(1):19-26.

51. Orasan MS, Roman II. Evaluation of Psoriasis Patients. In Tailored Treatments in Psoriatic Patients. 2018;79763:1-28.

52. Haddad A, Chandran V. How can psoriatic arthritis be diagnosed early? Current Rheumatology Reports. 2012;14(4):358-63.

53. Murphy G, Reich K. In touch with psoriasis: topical treatments and current guidelines. Journal of the European Academy of Dermatology and Venereology. 2011;25 (Suppl 4):3-8.

54. Robinson A, Voorhees ASV, Hsu S, Korman NJ, Lebwohl MG, JrBebo BF, et al. Treatment of pustular psoriasis: from the Medical Board of the National Psoriasis Foundation. Journal of the American Academy of Dermatology. 2012;67(2):279-88.

55. WHO Expert Committee on the Selection, Use of Essential Medicines, World Health Organization. The Selection and Use of Essential Medicines: Report of the WHO Expert Committee, 2013 (including the $18^{\text {th }}$ WHO Model List of Essential Medicines and the $4^{\text {th }}$ WHO Model List of Essential Medicines for Children). World Health Organization. 2014.

56. Dogra S, Kaur I. Childhood psoriasis. Indian Journal of Dermatology: Venereology and Leprology. 2010;76(4):357.

57. Bhutani T, Kamangar F, Cordoro KM. Management of pediatric psoriasis. Pediatric Annals. 2012;41(1):e11-7.

58. Torsekar R, Gautam MM. Topical therapies in psoriasis. Indian Dermatology Online Journal. 2017;8(4):235.

59. Ring J, Alomar A, Bieber T, Deleuran M, Fink-Wagner A, Gelmetti C, et al. Guidelines for treatment of atopic eczema (atopic dermatitis) part I. Journal of the European Academy of Dermatology and Venereology. 2012;26(8):1045-60.

60. Nghiem P, Pearson G, Langley RG. Tacrolimus and pimecrolimus: from clever prokaryotes to inhibiting calcineurin and treating atopic dermatitis. Journal of the American Academy of Dermatology. 2002;46(2):228-41.

61. Shah KN. Diagnosis and treatment of pediatric psoriasis: current and future. American Journal of Clinical Dermatology. 2013;14(3):195-213.

62. Sticherling M, Augustin M, Boehncke WH, Christophers E, Domm S, Gollnick H, et al. Therapy of psoriasis in childhood and adolescence-a German expert consensus. JDDG: Journal Der Deutschen Dermatologischen Gesellschaft. 2011;9(10):815-23.

63. Thomas J, Parimalam K. Treating pediatric plaque psoriasis: challenges and solutions. Pediatric Health, Medicine and Therapeutics. 2016;7:25-38.

64. Garg T, Rath G, Goyal AK. Ancient and Advanced Approaches for the Treatment of an Inflammatory Autoimmune Disease-Psoriasis. Critical Reviews in Therapeutic Drug Carrier Systems. 2014;31(4).

65. Gelmetti C. Therapeutic moisturizers as adjuvant therapy for psoriasis patients. American Journal of Clinical Dermatology. 2009;10(1):7-12.

66. Torsekar R, Gautam MM. Topical therapies in psoriasis. Indian Dermatology Online Journal. 2017;8(4):235.

67. Agrawal U, Gupta M, Dube D, Vyas SP. Options and opportunities for clinical management and treatment of psoriasis. Critical Reviews in Therapeutic Drug Carrier Systems. 2013;30(1).

68. Vangipuram R, Feldman SR. Ultraviolet phototherapy for cutaneous diseases: a concise review. Oral diseases. 2016;22(4):253-9.

69. Balk SJ. Ultraviolet radiation: a hazard to children and adolescents. Pediatrics. 2011;127(3):e791-817.

70. Nast A, Boehncke WH, Mrowietz U, Ockenfels HM, Philipp S, Reich K, et al. S3-Guidelines on the treatment of psoriasis vulgaris (English version). Update. JDDG: Journal der Deutschen Dermatologischen Gesellschaft. 2012;10 (Suppl 2):S1-95.

71. Menter A, Korman NJ, Elmets CA, Feldman SR, Gelfand JM, Gordon KB, et al. Guidelines of care for the management of psoriasis and psoriatic arthritis: Section 5 . Guidelines of care for the treatment of psoriasis with phototherapy 
and photochemotherapy. Journal of the American Academy of Dermatology. 2010;62(1):114-35.

72. Kalb RE, Fiorentino DF, Lebwohl MG, Toole J, Poulin Y, Cohen AD. et al. Risk of serious infection with biologic and systemic treatment of psoriasis: results from the Psoriasis Longitudinal Assessment and Registry (PSOLAR). JAMA Dermatology. 2015;151(9):961-9.

73. Guenther LC. Combination therapy of biologics with traditional agents in psoriasis. Skin Therapy Lett. 2011;16(6):1-3.

74. Polat M, Lenk N, Yalcin B, Gür G, Tamer E, Artuz F, et al. Efficacy of erythromycin for psoriasis vulgaris. Clinical and Experimental Dermatology: Clinical Dermatology. 2007;32(3):295-7.

75. Thaci D, Bräutigam M, Kaufmann R, Weidinger G, Paul C, Christophers E. Body-weight-independent dosing of cyclosporine micro-emulsion and three times weekly maintenance regimen in severe psoriasis. Dermatology. 2002;205(4):383-8.

76. DiLernia V, Stingeni L, Boccaletti V, Calzavara PPG, Guarneri C, et al. Effectiveness and safety of cyclosporine in pediatric plaque psoriasis: a multicentric retrospective analysis. Journal of Dermatological Treatment. 2016;27(5):395-8.

77. Robinson A, Voorhees ASV, Hsu S, Korman NJ, Lebwohl MG, JrBebo BF, et al. Treatment of pustular psoriasis: from the Medical Board of the National Psoriasis Foundation. Journal of the American Academy of Dermatology. 2012;67(2):279-88.

78. Sbidian E, Maza A, Montaudié H, Gallini A, Aractingi S, Aubin F, et al. Efficacy and safety of oral retinoids in different psoriasis subtypes: a systematic literature review. Journal of the European Academy of Dermatology and Venereology. 2011;25(Suppl 2):28-33.

79. Beck KM, Yang EJ, Afifian L, Yan D, Bhutani T. Oral Agents for Psoriasis. In Evidence-Based Psoriasis. Springer, Cham. 2018;55-71.
80. Hajheydari Z, Sarparast L, Shahmohammadi S. Management of psoriasis in children: a narrative review. J Pediatr Rev. 2015;3(1):e131.

81. Dávila-Seijo P, Dauden E, Descalzo MA, Carretero G, Carrascosa JM, Vanaclocha $F$, et al. Infections in moderate to severe psoriasis patients treated with biological drugs compared to classic systemic drugs: findings from the BIOBADADERM Registry. Journal of Investigative Dermatology. 2017;137(2):313-21.

82. Braun J, Baraliakos X, Listing J, Sieper J. Decreased incidence of anterior uveitis in patients with ankylosing spondylitis treated with the anti-tumor necrosis factor agents infliximab and etanercept. Arthritis and Rheumatism: Official Journal of the American College of Rheumatology. 2005;52(8):2447-51.

83. Tobin AM, Kirby B. TNFa inhibitors in the treatment of psoriasis and psoriatic arthritis. Bio Drugs. 2005;19(1):47-57.

84. Kaushik SB, Lebwohl MG. Psoriasis: Which therapy for which patient: Focus on special populations and chronic infections. J Am Acad Dermatol. 2019;80(1):43-53.

85. Cuchacovich R, Espinoza CG, Virk Z, Espinoza LR. Biologic therapy (TNF- $\alpha$ antagonists)-induced psoriasis: a cytokine imbalance between TNF- $\alpha$ and IFN- $\alpha$ ?. JCR: Journal of Clinical Rheumatology. 2008;14(6):353-6.

86. Guida B, Napoleone A, Trio R, Nastasi A, Balato N, Laccetti R, et al. Energyrestricted, $n-3$ polyunsaturated fatty acids-rich diet improves the clinical response to immuno-modulating drugs in obese patients with plaque-type psoriasis: a randomized control clinical trial. Clinical Nutrition. 2014;33(3):399405.

87. Rahman M, Beg S, Ahmad MZ, Kazmi I, Ahmed A, Rahman Z, et al. Omega-3 Fatty Acids as Pharmacotherapeutics in Psoriasis: Current Status and Scope of Nanomedicine in its Effective Delivery. Current Drug Targets. 2013;14(6):708-22.

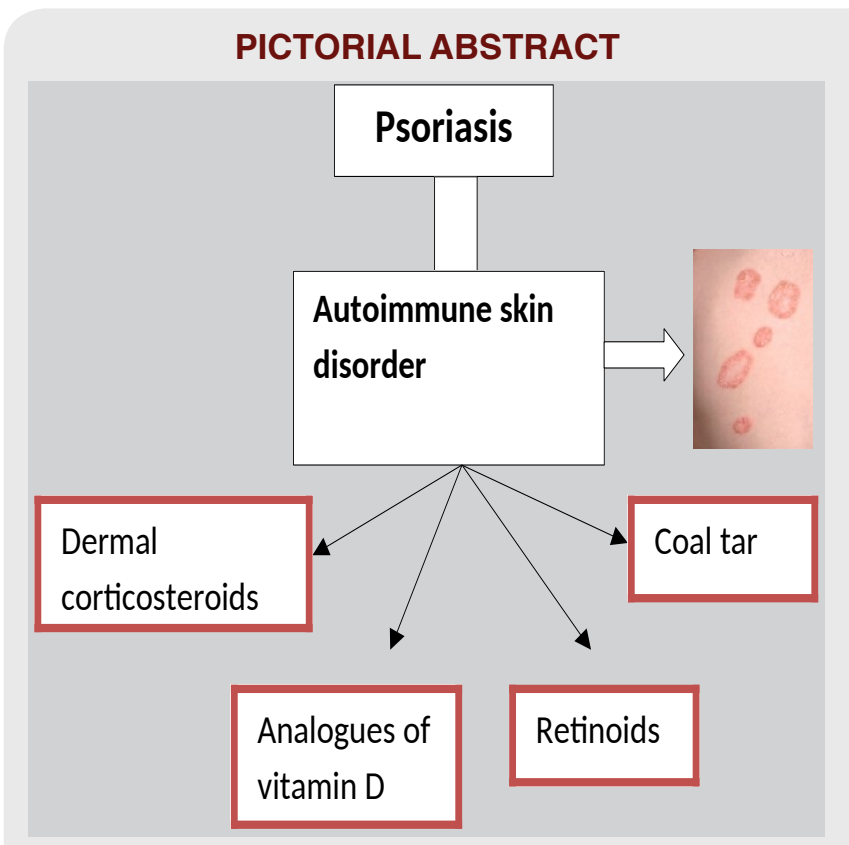

\section{SUMMARY}

Psoriasis is a typical, inflammatory, autoimmune skin disorder escalating among children. Manifestation in children is identical to the pattern in adult patients, with the scalp, areas behind the auricle of ears, hands and knees being most affected. There are different types of psoriasis and its severity grading is usually based on surface area. Approaches to delay or prevent co-morbidities and to reduce the burden of disease is of immediate concern in treating them. Various pharmacotherapeutic agents are available to improve the quality of life of psoriatic victims, but lack of effective guidelines makes the treatment challenging in children. As psoriasis requires long-term therapy, drugs with marginal safety index should be avoided to reduce various complications. Information provided on classification, indication, dosages and the risks of each of the major therapeutic agents may help the health care providers in selecting the appropriate drug or combination of drugs in treating pediatric psoriasis. 


\section{About Authors}

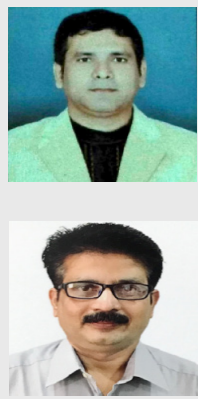

Dr. Sarfaraz Ahmad, Assistant Professor, Pharmacy Practice Research Unit, Department of Clinical Pharmacy, Jazan University, Jizan, KSA.

Dr. David Banji, Professor, Pharmacy Practice Research Unit, Department of Clinical Pharmacy, Jazan University, Jizan, KSA.
Dr. Ahmed A. Albarraq, Associate Professor and ViceDean for PG Studies and Research is a senior faculty in the College of Pharmacy, Jazan University, Jizan, KSA.

Dr. Saad S. Alqahtani, Assistant Professor and Head of the Department of Clinical Pharmacy. He is also the Chairman of Pharmacy Practice Research Unit, College of Pharmacy, Jazan University, Jizan, KSA.

Cite this article: Albarraq AA, Alqahtani SS, Ahmad S, Banji D. Prevalence and Pharmacotherapeutic Management of Pediatric Psoriasis-A Descriptive Review. Indian J of Pharmaceutical Education and Research. 2019;53(4):56976. 